\title{
PENGUKURAN MUTU LAYANAN DAN KEPUASAN MASYARAKAT WAJIB PAJAK (SURVEY PADA KANTOR PELAYANAN PAJAK PRATAMA X)
}

\author{
Abdul Haris, Arif Julianto Sri Nugroho, Anis Marjukah \\ Prodi Manajemen Fakultas Ekonomi Universitas Widya Dharma Klaten \\ e-mail: arifjuliantosn72@gmail.com
}

\begin{abstract}
RINGKASAN
Tantangan yang harus dihadapi Indonesia saat ini berupa penerimaan sektor pajak yang menyumbang lebih dari 80 persen dari total penerimaan negara. Amanah UU no 25 tahun 2009 tentang pelayanan publik mengamanahkan seluruh instansi pemerintah wajib memberikan pelayanan yang optimal dan berkualitas kepada masyarakat. Tujuan penelitian adalah menganalisis model indeks kepuasan masyarakat dari mutu layanan Kantor Pajak Pratama X dengan menganalisis gap setiap unsur layanan. Metode penelitian yang akan digunakan berupa riset kuantitatif uji gap/ kesenjangan antara harapan dan persepsi mutu layanan. Responden yang diambil sebanyak 120 orang wajib pajak dengan teknik sampling purposive. Uji kuantitatif dilakukan berupa uji gap Servqual. Hasil akhir diperoleh semua dimensi masih memiliki nilai kesenjangan dengan nilai gap terbesar pada dimensi responsiveness. Pihak pemangku kepentingan harus memperbaiki mutu layanan dengan prioritas dari nilai negatif terbesar sehingga tercipta optimalisasi mutu layanan yang bermuara pada meningkatnya kepuasan masyarakat
\end{abstract}

Kata kunci: Servqual, harapan, persepsi, kepuasan

\section{ABSTRACT}

This study tries to identify the most important dimension to examine the level of service quality with Servqual model, expectation and perception of external customer toward the $X$ Pratama Tax Office with 120 respondences as a purposive samples.

The research illustrates that Servqual model as a useful managerial tool can allocated in order to improve and enchange the quality of service the institution. Finally, these external customers have the highest expectation on responsiveness of the $X$ Pratama TaxOffice

Keywords: Servqual, expectation, perception, satisfaction

\section{PENDAHULUAN}

Peran penerimaan pajak penting bagi suatu negara. Pemerintah setiap tahun selalu mengupayakan agar penerimaan di sektor perpajakan dapat meningkat. Pajak merupakan salah satu elemen penting dalam mengelola pendapatan nasional, terutama di negara maju dan telah memainkan peran penting dalam masyarakat beradab sejak ribuan tahun yang lalu.
Di Indonesia Direktorat Jenderal Pajak merupakan tonggak Pemerintah dalam mengelola sektor perpajakan, maka peningkatan pajak yang sudah dicapai merupakan salah satu indikator kinerja Dirjen Pajak. Penerimaan dari sektor pajak meningkat setiap tahunnya dan memiliki proporsi yang lebih besar daripada penerimaan selain sektor pajak. Data Kemenkeu tahun 2019 [1] pada APBN 2018 penerimaan perpajakan 
Research Fair Unisri 2019

Vol 4, Number 1, Januari 2020

sebesar 1.786,4 trilyun memiliki porsi 82

persen dari pendapatan negara sebesar

2.165,1 trilyun. Namun beberapa permasalahan mengenai perpajakan masih harus dihadapi oleh Pemerintah Indonesia saat ini terkait tax ratio yang masih rendah. Tax ratio merupakan perbandingan jumlah penerimaan pajak dengan PDB suatu negara. Saat ini angka tax ratio Indonesia baru mencapai 12,2\% [1]. Sedangkan tax ratio yang diharapkan sebenarnya sebesar $22 \%$ sehingga tax gap nya Indonesia mencapai hampir 100 $\%$. Hal ini sangat ironis dibandingkan negara-negara tetangga ASEAN yang bisa mencapai angka 17-20\%, bahkan negara-negara maju seperti negara Inggris yang mencapai 27-30 \%. Rendahnya tax ratio disebabkan kurangnya intensifikasi dan ekstensifikasi sektor perpajakan. Disamping itu disebabkan pula masih terbatasnya tenaga trampil yang menguasai seluk beluk perpajakan di Indonesia.

Kenyataan di lapangan pada tahun lalu, pelaksanaan program amnesty pajak masih banyak ditemui kendala mutu layanan dari pihak pegawai kantor pajak dalam melayani masyarakat sehingga perlu diteliti lebih lanjut terkait kualitas layanan. Dari beberapa persoalan dari latar belakang masalah perlu dilakukan pengukuran mutu layanan wajib pajak di kantor Pajak Pratama X, sehingga rumusan masalah
P- ISSN: 2550-0171

E- ISSN: 2580-5819

utama penelitian : "Apakah mutu layanan wajib pajak dari Kantor Pajak Pratama X belum memuaskan masyarakat?"

\section{METODE PENELITIAN}

\section{Metode Pengumpulan Data}

Metode penelitian yang digunakan dalam penelitian ini adalah metode survai. Sekaran [2] menjelaskan survey bertujuan mencari informasi secara langsung dari responden dengan menggunakan kuesioner. Atau dengan kata lain menurut Singarimbun [3] metode survei adalah suatu penelitian yang mengambil sampel dari populasi dan menggunakan kuesioner sebagai alat pengumpulan data pokok

\section{Data yang diperlukan}

Data Primer, yaitu data yang diperoleh secara langsung dari sumber yang memiliki pemahaman terhadap obyek yang diteliti. Dengan penyebaran kuesioner, diharapkan akan diperoleh informasi mengenai kualitas layanan pegawai kantor pajak di KPP Pratama X beserta informasi tingkat kepuasan masyarakat wajib pajak.

Data sekunder, yaitu data yang diperoleh dari sumber-sumber kepustakaan catatan atau arsip institusi serta sumber-sumber lain yang berkaitan dengan penelitian.

\section{Teknik Pengumpulan Data}

Wawancara, dilakukan untuk memperoleh hal-hal yang berkaitan 
Research Fair Unisri 2019

Vol 4, Number 1, Januari 2020

dengan gambaran umum institusi serta perencanaan strategi yang telah dilakukan

Untuk memperoleh informasi tentang kepuasan layanan, peneliti menyebarkan kuesioner secara acak kepada masyarakat yang telah mendapatkan layanan admisnistrasi pajak di KPP Pratama X. Studi Pustaka, dilakukan untuk memperoleh data pendukung yang diperlukan.

\section{Metode Pengambilan Sampel}

Dalam penelitian ini, metode survei digunakan sebagai alat utama. Dengan demikian tidak semua individu dalam populasi diteliti karena keterbatasan waktu, biaya dan aksesbilitas. Untuk itu digunakan metode sampling dengan cara sebagai berikut: Populasi, adalah keseluruhan dari jumlah unit analisis yang ciri-cirinya akan diduga, yang dimaksud populasi dalam penelitian ini adalah seluruh masyarakat di Soloraya yang pernah mendapatkan pelayanan admistrasi kantor Pajak

\section{Teknik Pengambilan Sampel}

Karakteristik subyek yang akan dipakai sebagai sampel dalam penelitian ini sejumlah 120 orang masyarakat pemakai jasa layanan KPP Pratama X secara non random sampling melalui purposive sampling. Selain itu subyek dalam penelitian ini adalah individu dewasa, dengan anggapan mereka memiliki pertimbangan masak dalam menilai bagaimana mutu yang diberikan pegawai kantor pajak Pratama $\mathrm{X}$ dalam melayani masyarakat dan dapat
P- ISSN: 2550-0171

E- ISSN: 2580-5819

merasakan

kepuasan

maupun

ketidakpuasan dari layanan tersebut.

\section{Metode Analisis Data}

\section{Uji Konfirmasi Masyarakat}

Analisis ini diukur dengan menggunakan gap ke-5 dengan metode Weighted ServQual Cronin \& Taylor [4]:

$$
\begin{aligned}
& \mathbf{I} \mathbf{k j}=\sum(\mathbf{P} \text { ij-E } \mathbf{i j}) \\
& \text { I kj = Indek konfirmasi terhadap objek j } \\
& \text { I kj }<0 \text { Konfirmasi negatif/tidak puas } \\
& \text { I kjb } \geq 0 \text { Konfirmasi positif/puas } \\
& \text { P ij = kinerja atribut i pada objek j } \\
& \text { E ij = harapan atribut i pada objek j }
\end{aligned}
$$

\section{HASIL DAN PEMBAHASAN}

$$
\text { Untuk menguji tingkat }
$$
konfirmasi masyarakat pemakai layanan Kantor PP Pratama X digunakan rumus Weighted Servqual Cronin \& Taylor [4]. Dari uji tersebut dapat dihitung total nilai konfirmasi dari mutu layanan Kantor Pajak Pratama - 87.27. Nilai konfirmasi maksimum atau minimum dengan jumlah responden sebanyak 120 orang yang dicapai Ikj $\max =420$ dan Ikj min - 420

Nilai konfirmasi maksimum yang dicapai diasumsikan bahwa masyarakat memiliki harapan minimal terhadap mutu layanan yang akan diterima dan merasakan kinerja aktual yang maksimum terhadap mutu layanan yang diterima. Demikian sebaliknya, nilai konfirmasi minimum yang dapat dicapai bahwa masyarakat memiliki harapan maksimum terhadap mutu layanan yang akan diterima, tetapi 
Research Fair Unisri 2019

Vol 4, Number 1, Januari 2020

kenyataannya merasakan kinerja aktual minimum atas mutu layanan yang diterima.

Dari perhitungan kuantitatif, diperoleh nilai konfirmasi masyarakat terhadapa Kantor Pajak Pratama X memiliki interval sebesar 840, angka tersebut dibagi dalam 4 skala tingkat konfirmasi : sangat tidak puas, tidak puas, puas dan sangat puas, menurut preferensi nasabah sehinggga didapat range sebesar 210 poin.

Gambar 1 menunjukkan

konfirmasi nasabah terhadap mutu layanan KPP Pratama X dalam suatu interval:

Sgttidakpuas tidak puas Netral Puas sangat puas

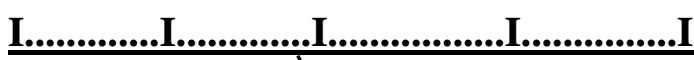
$\begin{array}{ccc}-420 & -210 & 0 \\ \text { Konfirmasi mutu layanan KPP Pratama X }(-87.27)\end{array}$

\section{Gambar 1}

\section{Konfirmasi masyarakat terhadap mutu} layanan KPP Pratama X

Gambar diatas dapat disimpulkan bahwa nilai konfirmasi terhadap mutu layanan KPP Pratama X sebesar -87. 27 berada pada interval antara 0 sampai - 210 dengan kategori tidak puas. Standar minimal yang harus dicapai untuk memperoleh tingkat kepuasan layanan apabila nilai konfirmasi mencapai nilai sama dengan 0 atau lebih ( konfirmasi $\geq$ 0), dari hasil perhitungan tersebut, berarti kepuasan mutu layanan penerima layanan KPP Pratama X belum tercapai.

Setelah diperoleh uji konfirmasi secara menyeluruh, diurai kesenjangan
P- ISSN: 2550-0171

E- ISSN: 2580-5819

masing-masing dimensi mutu layanan sesuai konsep Parasuraman [5] meliputi dimensi keandalan, bukti fisik, daya tanggap, jaminan dan empati pada tabel 1

Tabel 1 kesenjangan per dimensi

\begin{tabular}{|l|c|}
\hline \multicolumn{1}{|c|}{ Dimensi } & Tingkat Konfirmasi \\
\hline Keandalan & -67 \\
Bukti fisik & -65.50 \\
Daya tanggap & -87.27 \\
Jaminan & -73.50 \\
Empati & -85.36 \\
\hline
\end{tabular}

Dari tabel diperoleh data dimensi daya tanggap memiliki nilai kesenjangan negatif terbesar senilai -87.27 secara berturut-turut diikuti empati sebesar 85.36, jaminan sebesar -73.50 , dimensi keandalan sebesar - 67 dan terakhir dimensi bukti fisik - 65.5. Dimensi daya tanggap berkaitan dengan kemampuan respon yang cepat KPP Pratama X dalam melayani masyarakat. Dimensi yang memiliki nilai gap terbesar harus diprioritaskan dalam perbaikan mutu layanan, kemudian beralih pada prioritas dimensi berikutnya. Dengan kata lain untuk meningkatkan kepuasan masyarakat, pihak KPP Pratama X harus memprioritaskan peningkatan mutu layanan pada dimensi yang memiliki nilai kesenjangan terbesar.

\section{KESIMPULAN}

Setelah dilakukan pembahasan dituangkan beberapa simpulan sebagai berikut :

1. Standar yang harus dicapai untuk memperoleh tingkat kepuasan 
minimum apabila nilai

konfirmasi mencapai nilai sama dengan nol atau lebih (Konfirmasi $\geq 0$ ). Hasil uji konfirmasi didapat nilai sebesar 87,27 . Nilai konfirmasi minimum yang dapat dicapai oleh pelayanan KPP Pratama X sebesar - 420. Sedangkan nilai konfirmasi maksimum yang dapat dicapai sebesar 420. Artinya, tingkat kepuasan terhadap mutu layanan yang dirasakan masyarakat minus sebesar 20 persen dari tingkat kepuasan maksimum. Untuk mencapai tingkat kepuasan minimum pihak Kantor PP Pratama X harus mampu menutup kesenjangan sebesar 20 persen dari tingkat kepuasan minimum. Disini dapat disimpulkan KPP Pratama X belum mampu memberikan kepuasan pada mutu layanan yang diharapkan.

2. Hasil uji nilai konfirmasi masyarakat pada masing-masing dimensi mutu layanan diperoleh informasi dimensi daya tanggap memiliki kesenjangan negatif terbesar senilai -87.27 secara berturut-turut diikuti empati sebesar -85.36, jaminan sebesar 73.50, keandalan sebesar - 67 dan terakhir dimensi bukti fisik 65.5. Berdasarkan hasil ujii konfirmasi, pihak KPP Pratama dalam meningkatkan mutu pelayanan harus memprioritaskan pada dimensi-dimensi yang memiliki nilai negatif terbesar, dilanjutkan pada nilai negatif berikutnya. Kunci pemasaran menurut Kotler [6] segala kegiatan yang kesemuanya bertujuan memuaskan konsumen

3. Nilai konfirmasi kepuasan negatif menunjukkan bahwa Kantor PP Pratama $\mathrm{X}$ belum mampu memberikan mutu layanan profesional sesuai harapan masyarakat wajib pajak

\section{Saran}

Dari simpulan diajukan saran sebagai berikut :

1. Pihak KPP Pratama $X$ harus terus berbenah untuk terus meningkatkan mutu layanan kepada wajib pajak sehingga muncul kepatuhan masyarakat untuk sadar membayar pajak secara sukarela

2. Pihak Manajemen KPP Pratama $\mathrm{X}$ secara periodik harus terus mengadakan survai mutu layanan. Hal ini perlu dilakukan karena harapan akan mutu layanan selalu berubah terkait waktu dan kondisi, dilain pihak semakin tinggi dan kritis pula tuntutan masyarakat pembayar 
pajak terhadap profesionalisme layanan pegawai kantor Pajak

\section{DAFTAR PUSTAKA}

[1] Kemenkeu, 2019, Data APBN 2018, www.kemenkeu.go.id

[2] Sekaran, Uma, 2016. Research Methods for Business, A Skill Building Approach, $7^{\text {nd }}$ ed. John Willey \& Sons, Inc

[3] Singarimbun, Masri, Effendi Sofian. 2003. Metode Penelitian Survey, jakarta: LP3ES

[4] Cronin JJ, taylor SA, 2002. “ Mesuring Service Quality: A Reexamination and Extension ". Journal of Marketing 6: 55-68

[5] Parasuraman, A., A., Zeithamal, V., \& I. Berry, L, 2005."A Conceptual Model of Service Quality and Its Implication”, Journal of Marketing, Vol. 49 (fall) pp 41-50

[6] Kotler, Phillip, 2009. Marketing Management: Analysis, Planning, Implementation, and Control $\left(13^{\text {th }}\right.$ Ed). New Jersey: Prentice Hall 